\title{
COMPARATIVE STUDY BETWEEN THE USE OF AMNIOTIC MEMBRANE AND FIBRIN GLUE FOR THE REPAIR OF PERFORATED MAXILLARY SINUS (AN EXPERIMENTAL STUDY)
}

\author{
Maather A. Selim ${ }^{*} B D S$, Ahmed M. Shaaban ${ }^{2} P h D$, Hala R. Ragab ${ }^{3} P h D$, \\ Nesma M. Khalil ${ }^{4} \mathrm{PhD}$
}

\section{ABSTRACT}

INTRODUCTION: Maxillary sinus membrane perforation is the most common intraoperative complications associated with the sinus lifting procedure. There are various sutureless techniques used in repairing of perforated sinus membrane including; collagen membrane, fibrin sealants, cyanoacrylate adhesives,amniotic membrane and fibringlue.

OBJECTIVES: The aim of this study was to compare between the use of amniotic membrane and fibrin glue in healing of perforated maxillary sinus in rabbits.

MATERIALS AND METHOD: This study was conducted on ten adult healthy male rabbits, with an average weight between 2-3 kgs. A split mouth design was implemented. In each rabbit, the right sinus membrane window was repaired by fibrin glue (group I), while the left sinus membrane window was repaired by amniotic membrane (group II).

RESULTS: Histological results revealed that amniotic membrane enhanced faster reepithelialization of maxillary sinus membrane and bone healing where the amount of the newly formed bone observed in group II was greater than that of group I. Histomorphometric analysis showed the increase in the bone surface area mean percentage in group II in comparison to group I.

CONCLUSION: According to the results of the present study, it was concluded that the amniotic membrane is effective in the repair of perforated sinus membrane with superior potentiality than fibrin glue especially in the early stage.

KEY WORDS: Maxillary sinus repair, Amniotic membrane, Fibrin glue, Sutureless technique.

RUNNING TITLE: Sinus repair using amniotic membrane \& fibrin glue.

1 BDS, 2006, faculty of dentistry, Alexandria University, Alexandria, Egypt.

2 Professor of Oral Maxillofacial Surgery, faculty of dentistry, Alexandria University, Alexandria, Egypt.

3 Assistant professor of Oral Maxillofacial Surgery, faculty of dentistry, Alexandria University, Alexandria, Egypt.

4 Lecturer of Oral Biology, faculty of dentistry, Alexandria University, Alexandria, Egypt.

*Corresponding author

E-mail: myloaloa2011@gmail.com

\section{INTRODUCTION}

The most prevalent intra-operative complication associated with the sinus elevation procedure is perforation of the Schneiderian membrane. Small sinus membrane perforations are not an absolute contraindication to the surgery continuation because they may be adequately repaired and covered provided that they do not allow graft material passage inside the maxillary sinus; Implants survival rates are inversely proportional to the perforations size (1).

But in case of larger perforation, interruption of the surgery is a must, and the site must be hermetically sealed. As has been reported in the literature, large perforations are an absolute contraindication to surgery continuation, especially if the form of graft material is granular or chip which may cause the graft loss into the sinus, leading to graft infection and implant procedure early failure $(2,3)$.

Repair of sinus membrane can be troublesome and doubtful for both large perforations and completely teared membranes, so suturing is not possible due to the difficulty of membrane edges approximation. In addition, these membranes are thin which may lead to tearing upon suturing (4).
The sinus membrane perforation repaired by various sutureless techniques including; collagen membranes, cyanoacrylate adhesives, fibrin sealants and autologous fibrin glue have been proposed for managing these perforations (5-8).

Two methods are commonly used for such perforations; one involves a resorbable membrane and the other involves fibrin glue (4).

Fibrin glue is an adhesive, which was developed as a result of fibrinogen solidification forming fibrin nets during the healing process; these nets have an adhesive action. Several reports are available on closing the antral perforations using fibrin glue. There are cases in which small perforations closure was successfully achieved without graft material loss (7-9).

Amniotic membrane (AM) is the fetal membrane innermost layer lining the amniotic cavity. It is a translucent tissue devoid of any vasculature. Its thickness is from 0.02 to $0.5 \mathrm{~mm}$, it consists of five layers. In contact with the amniotic fluid there is a single cell layer resting on its basement membrane. Then there are three other layers, namely a compact layer, comprised in the underlying connective tissue attaching the basement membrane, then 
another two layers connected with the cellular layer of the chorion, namely the fibroblast layer and the spongy layer $(10,11)$.

The AM has many valuable properties, such as; its antibacterial activity, anti-angiogenic properties, inflammation suppression, anti-scarring action, nonimmunogenicity, pain relief, wound healing and epithelialization (12-14). In addition to its epithelial stem niche preservation ability, which is the reason why it is used in the treatment of ocular surface diseases (15).Moreover, it has been used as an acceptable membrane for vestibuloplasty surgery (16).

Moreover, cells of AM have pluripotent properties and, for this reason, are an excellent source for transplantation and tissue engineering $(17,18)$. There is differentiation potentiality of Amnion-derived cells into the three germ layers: endoderm, mesoderm and ectoderm.

The previously mentioned unique combination of properties of the AM is not found in any other natural or synthetic biocompatible material (9). That is why the aim of our experimental study was to compare between the effect of amniotic membrane and fibrin glue on healing of perforated maxillary sinus.

\section{MATERIALS AND METHOD}

\section{I- Experimental animals:}

This study was conducted on ten adult healthy male white New Zealand rabbits, weighed from $2-3 \mathrm{Kg}$. Animals were caged under the same nutritional and environmental conditions in the experimental animal house, the Physiology department, Faculty of Medicine, Alexandria University, after gaining the approval of the Research Ethics Committee of the faculty of Dentistry, Alexandria University.

A split mouth technique was implemented. In each rabbit, a bony window was prepared on maxillary sinus bilaterally. Then each side was assigned into one of the following groups:

1. Group I: the sinus membrane windows (the right side) were repaired by fibrin glue.

2. Group II: the sinus membrane windows (the left side) were repaired by amniotic membrane.

Five rabbits were sacrificed at each of the interval periods of 2 and 8 weeks.

\section{II- Materials:}

In the present study two materials were used.

(1) Fibrin glue: (Fibrogloo, manufactured by Cairo Medical Center Blood Bank (CMCBB). Distributed by: Premier Co. Roxy- New Egypt), which is a two-component preparation consisting of lyophilized human Thrombin and lyophilized human Fibrinogen.

\section{Identification:}

One vial containing a white, lyophilized, round cake of Thrombin. The vial is labeled: R1. One vial containing a pale yellow, lyophilized powder of Fibrinogen. The vial labeled: R2.

(2) Amniotic membrane , was prepared and preserved as follows:

A human donor mother was recognized who was submitted to cesarean section.
Some routine investigations such as HIV and Hepatitis B surface antigens were carried out. Clearance from the institutional ethical committee was obtained prior to the surgery.

In the operating room during the cesarean, the oral and maxillofacial surgeon delivered the placenta in a tray after its collection by the obstetrician. Then under sterile aseptic conditions the oral surgeon carefully separated the Amniotic Membrane (AM) from the chorion of the placenta. With copious amounts of tap water the clearance of AM from all blood clots and gross tissue attachment was done. In a large bottle containing $85 \%$ of glycerol the membrane was kept and stored in refrigerator at a temperature of $-80^{\circ} \mathrm{c}$. On the surgery day, the membrane was immersed in normal saline for a period of 10 minutes just before its application over perforated maxillary sinus of the rabbit.

This method of the AM preparation and preservation has been reported by Kesting et al (19) for the oronasal fistulas repair with human amniotic membrane in minipigs.

\section{III- Surgical procedure:}

All operating procedures were performed under the effect of sedation and general anesthesia. Sedation was performed by intramuscular (IM) injection of Xylazine $\mathrm{HCl}$ (XylaJect, Adwia Pharmaceuticals, 10th of Ramadan City Industrial Area, Egypt) $2 \mathrm{mg} / \mathrm{kg}$, followed by induction of anesthesia using Ketamine $\mathrm{HCl}$ (KetamineAlfasan 10\%, Woerden, Holland) $50 \mathrm{mg} / \mathrm{kg}$ IM.

The surgical procedure was performed under aseptic conditions for all animals. After shaving and disinfection of the surgical site with a povidone- iodine solution (Betadine, the NILE Co. for Pharmaceutical\& Chemical Ind. Cairo, Egypt), infiltration anesthesia with $2 \%$ articaine hydrochloride (Artpharmadent:Art pharma for pharmaceuticals. $6^{\text {th }}$ industrial zone, 6 October city, Giza, Egypt)was administrated to the nasal bone surgical sites.

A straight skin incision 3-4 cm with Bard Parker scalpel handle no.4 and a disposable blade no.24 on the nasal bone along the sagittal midline was done followed by a flap of full thickness elevated bilaterally.

Bilateral, Standardized, circular, bony windows were prepared on both maxillary sinus bony walls using a $6 \mathrm{~mm}$ diameter trephine bur, mounted on a low speed micro motor under copious irrigation with saline then the maxillary sinus membrane was elevated carefully from the bony walls of the antrum.

After elevation of sinus membrane a $5 \mathrm{~mm}$ perforation was done at center of the exposed membrane bilaterally. All the right sinus membrane windows were repaired by fibrin glue. While all left sinus membrane windows were repaired by amniotic membrane without any glue or sutures. (Fig.1). 

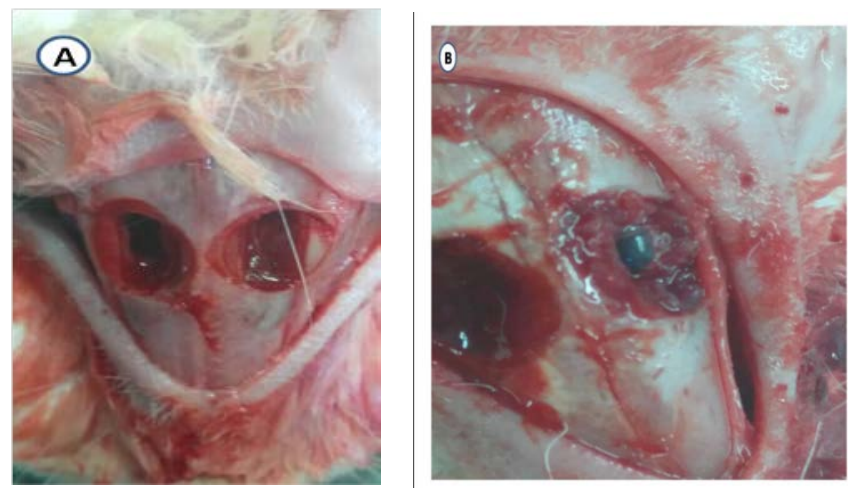

Fig. 1: A photograph showing, A: Perforations in the sinus membrane. B: Fibrin glue in the right window \& Amniotic membrane in the left window.

The wound was closed in layers, the periosteum sutured by 3/0 vicryl sutures (Polyglactin 910, synthetic absorbable suture material. Ethicon Ltd, UK.).Then the skin flaps were sutured with 3/0 black silk sutures (Silk braided Teleflex Medical OEM, Attn: Deknatel ${ }^{\circledR}$ Customer Care, 375 Forbes Boulevard, Mansfield, MA 02048-1805 USA. Fax: +1 508 964 6078).(20)

After the surgical procedure, all rabbits received Cefotax (Cefotaxime Sodium Egyptian Int. Pharmaceutical ind. A.R.E.)(50mg/kg/12hr) intramuscular and repeat the injection for the first five days postoperatively. Also, Voltaren (by NOVARTIS PHARMA S.A.E. CairoEgypt)analgesic was given for the first three days beginning immediately after surgery with a dose of $0.5 \mathrm{ml}$ intramuscular Care of the wound was carried out daily with povidone iodine solution.

Rabbits were euthanized at 2 and 8 weeks postoperatively, five rabbits at a time, with an over dose of intramuscular Phenobarbital sodium salt (Phenobarbital sodium salt: West-ward pharmaceuticals, Eaton town, USA.)

The maxillae were dissected out and segments containing the maxillary sinus were separated and fixed in $10 \%$ neutral buffered formalin.

\section{Histological preparations:}

The fixation of the specimens was followed by washing in distilled water, decalcification in $8 \%$ formic acid, dehydration in ascending grades of ethyl alcohol, clearance in xylene and paraffin embedded. Serial sections $(5 \mu)$ were sliced from paraffin blocks and stained with hematoxylin and eosin (H\&E) and were examined under light microscope to evaluate the healing procedure.

\section{Histomorphometric Evaluation:}

Morphometric evaluation of the percentage of surface area of the newly-formed bone (21) was assessed for each specimen using the (Image J 1.46) program.

Five coronal sections were cut from each specimen at different standardized depths. From each section, we captured an image using the same magnification power. In each image, one rectangle with standardized dimensions was drawn at the center. The surface area of the rectangle was measured and recorded.

Within each rectangle, the bone marrow spaces were selected using wand tracing tool, measured, and subtracted from the total area of the rectangle to obtain the area occupied only by bone.
The results were expressed as percentage values (the proportion of area occupied only by bone in relation to the total area of the standard rectangle). The same procedure was repeated for each of the five sections of the same specimen and the mean was obtained. The same procedure was repeated for each of the five specimens in each group. The used terminology was described by the Histomorphometry Nomenclature Committee of the American Society for Bone and Mineral Research (22).

\section{Statistical Analysis:}

Data were fed to the computer and analyzed using IBM SPSS software. The used tests were: Student t-test for normally distributed quantitative variables, to compare between two studied groups. ANOVA with repeated measures for normally distributed quantitative variables, to compare between more than two periods or stages, and Post Hoc test for pair wise comparisons.

\section{RESULTS}

\section{I-Clinical results:}

Animals showed uneventful wound healing within one week. There were no infections occurred during the postoperative periods.

\section{II-Histological results:}

The following observations were revealed after the examination of maxillary sinus of both group I and group II under transmitted light microscope.

\section{II.1. After two weeks:}

II.1.1.Group I (fibrin glue group) Re-epithelialization of the sinus membrane defect was seen by immature, discontinuous epithelium. The underlying lamina propria contained few serous acini although some areas appeared devoid of acini. Woven bone was seen in the defect area which consisted of thin bony spicules containing numerous large and haphazardly arranged osteocyte lacunae. The defect site was covered by a dense fibrous tissue (Fig.2).
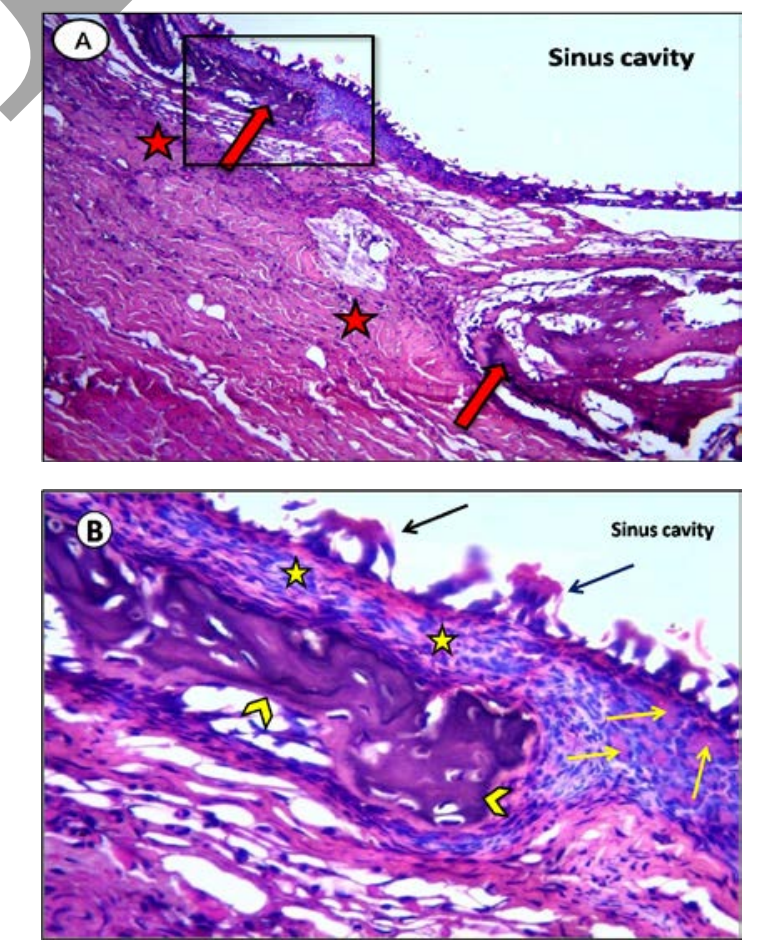
Fig 2: Light micrograph (LM) of maxillary sinus of group I ( 2 weeks). A: showing the defect area surrounded by the newly formed bone on each side (arrows). The healing area is covered by dense fibrous tissue (stars). B: High magnification of the previous inset showing the discontinuity of the epithelium (black arrows) lining the sinus cavity. The underlying lamina propria shows few serous acini (yellow arrows), while other areas appeared devoid of acini (stars). Newly formed immature bone can be seen (yellow arrow heads). (H\&E, A: x100, B: x400).

II.1.2. Group II (amniotic membrane group) the sinus membrane was repaired by an almost continuous layer of epithelium which consisted of pseudostratified ciliated columnar epithelium with many goblet cells. One of the outstanding finding in this group is the obvious vascularity of the lamina propria which contained also few scattered serous acini. Active bone formation was seen in the defect site, where woven bone was seen on each side of the defect. The bone consisted of many spicules surrounding well vascularized bone marrow spaces and contained large, irregularly arranged osteocyte lacunae. The amount of the newly formed bone observed in this group was more than seen in the control group. Large osteoblasts were detected covering the outer bone surface (Fig. 3).
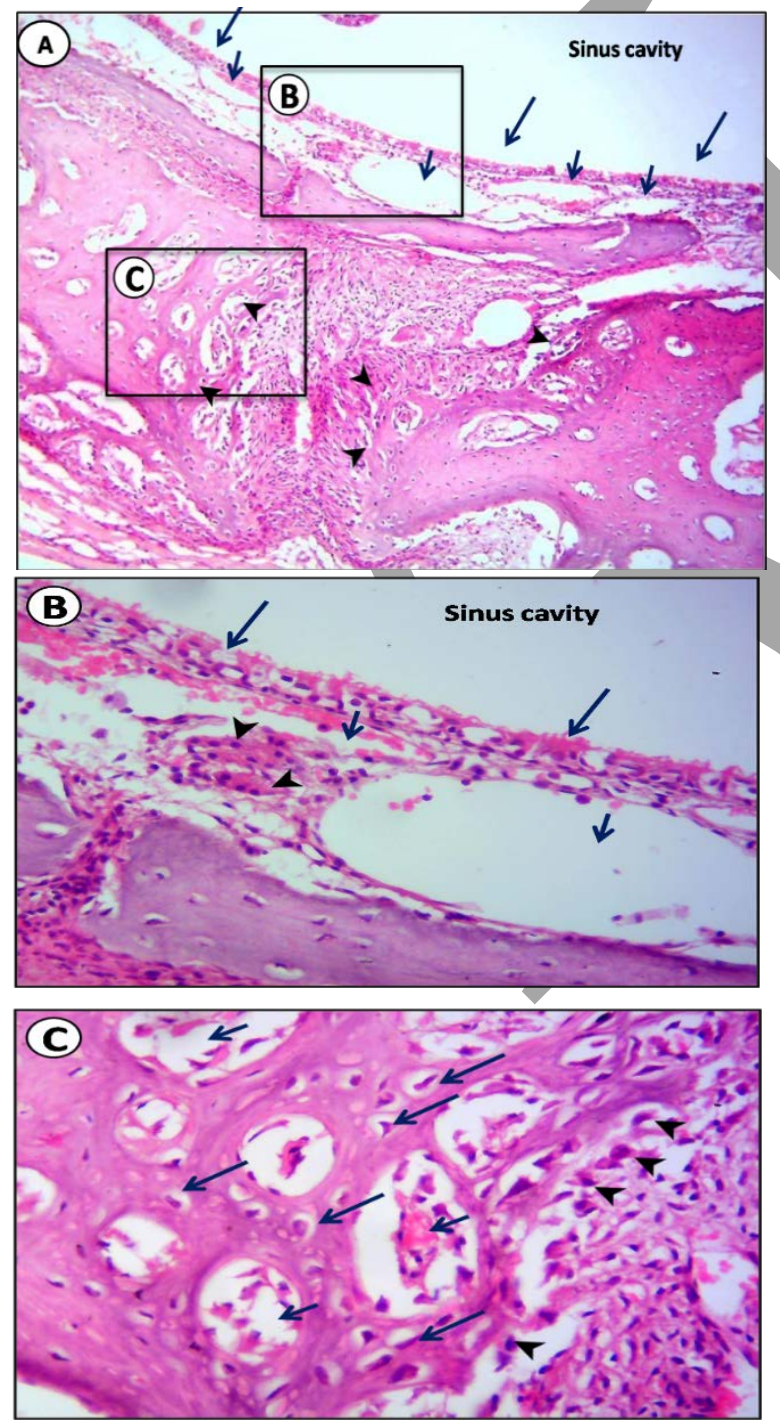

Fig. 3: LM of maxillary sinus of group II (2 weeks). A: showing healing of the sinus membrane by a continuous layer of pseudostratified ciliated columnar epithelium (long arrows). Note the obvious vascularity (short arrows) of the underlying lamina propria. Active bone formation is seen (arrow heads) on each side of the defect site. B: LM of higher magnification of the inset (B) in the previous micrograph showing the newly formed pseudostratified ciliated columnar epithelium with goblet cells and short cilia (long arrows). The lamina propria contains blood vessels (short arrows) lined by flat endothelial cells and one of them contains red blood corpuscles. Few serous acini (arrow heads) can be seen in the underlying connective tissue. C: LM of higher magnification of inset (C) showing the newly formed immature bone which contains high density of large osteocyte lacunae (long arrows) surrounding well vascularized bone marrow spaces (short arrows). Large and plump-looking osteoblasts (arrow heads) can be seen lining the outer surface of bone where active bone formation is taking place. (H\&E, A: x100, B,C: $\mathrm{x} 400$ )

\section{II.2. After eight weeks:}

II.2.1. Group I: The healing of the sinus defect was indicated by the continuity of the epithelial lining, presence of numerous serous acini in the underlying lamina propria, and the formation of mature lamellar bone. Remodeling was evident by the presence of reversal lines (Fig.4).

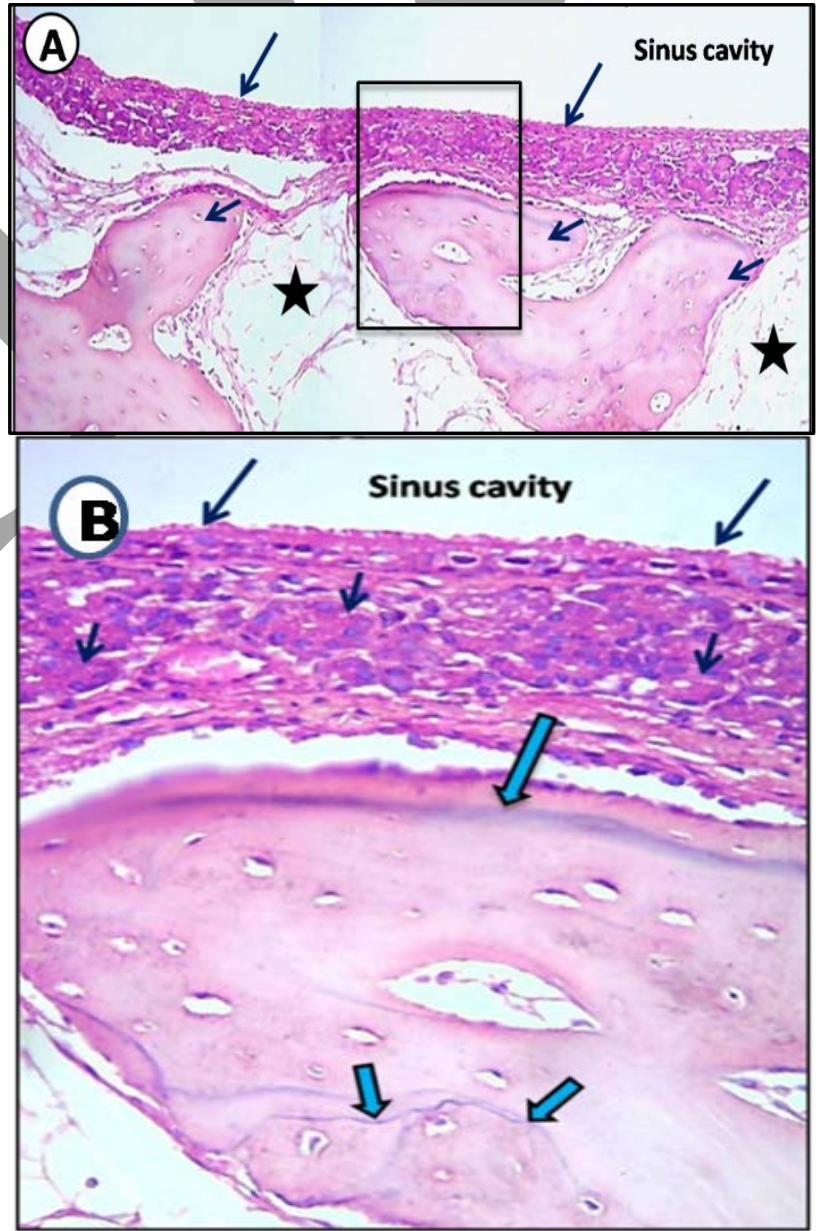

Fig. 4: LM of the maxillary sinus of group I (8 weeks). A: showing the repair of sinus defect by a continuous layer of sinus mucosa (long arrows). The underlying bone consists 
of thick cancellous bone trabeculae (short arrows) with wide marrow spaces (stars). B: LM of higher magnification of the previous micrograph inset showing the mature sinus mucosa which consists of pseudostratified ciliated columnar epithelium (long black arrows) and the underlying lamina propria which contains numerous serous acini (short black arrows). Cancellous bone contains resting line (long blue arrow) and numerous reversal lines (short blue arrows).). (H\&E, A: x100, B: x400).

II.2.2. Group II: Similar observations were seen similar to group I, however, one important observation was noted only in group II, which was the marked vascularity of the lamina propria of the sinus mucosa. Moreover, the trabeculae of the cancellous bone were thicker than those observed in group I (Fig. 5).
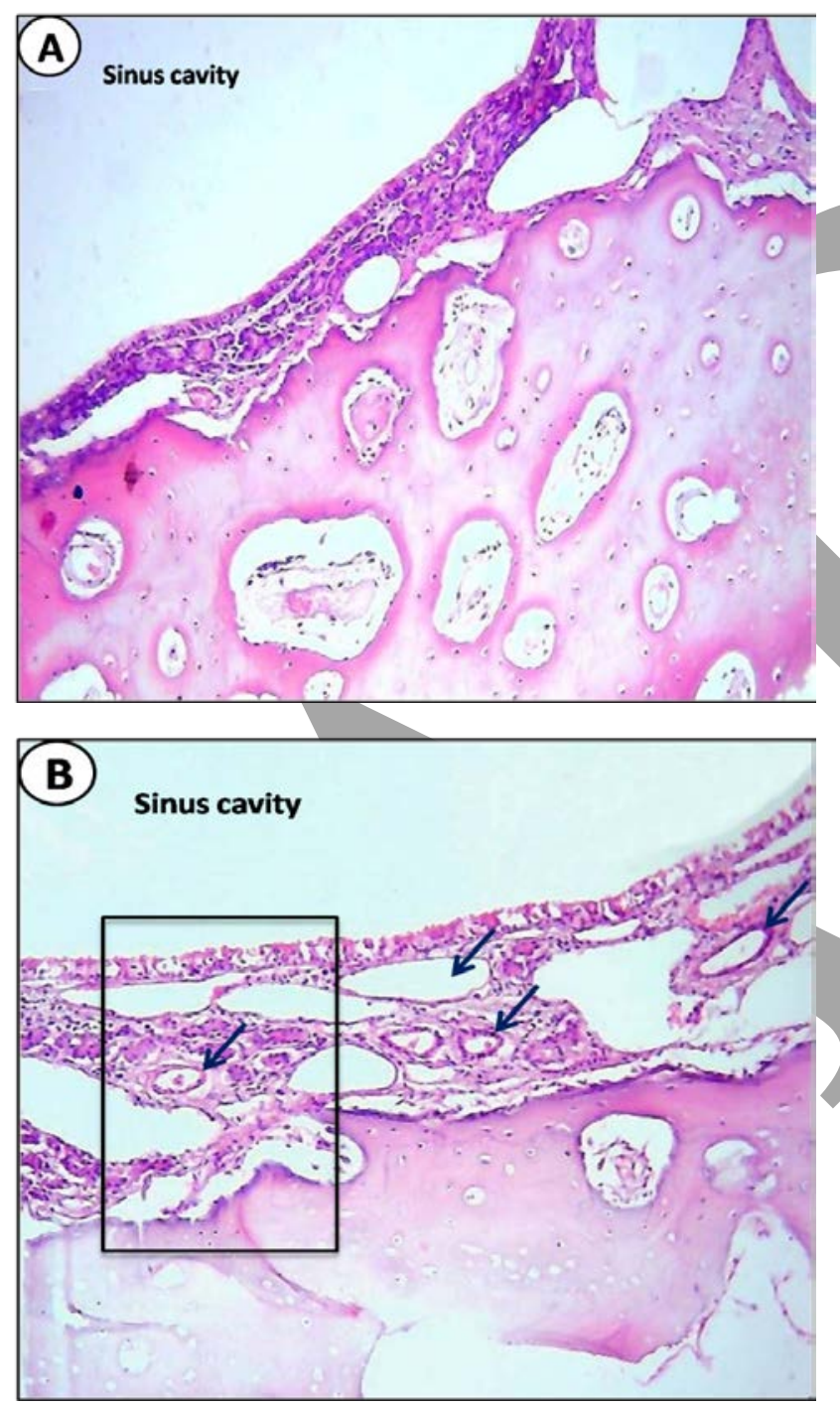

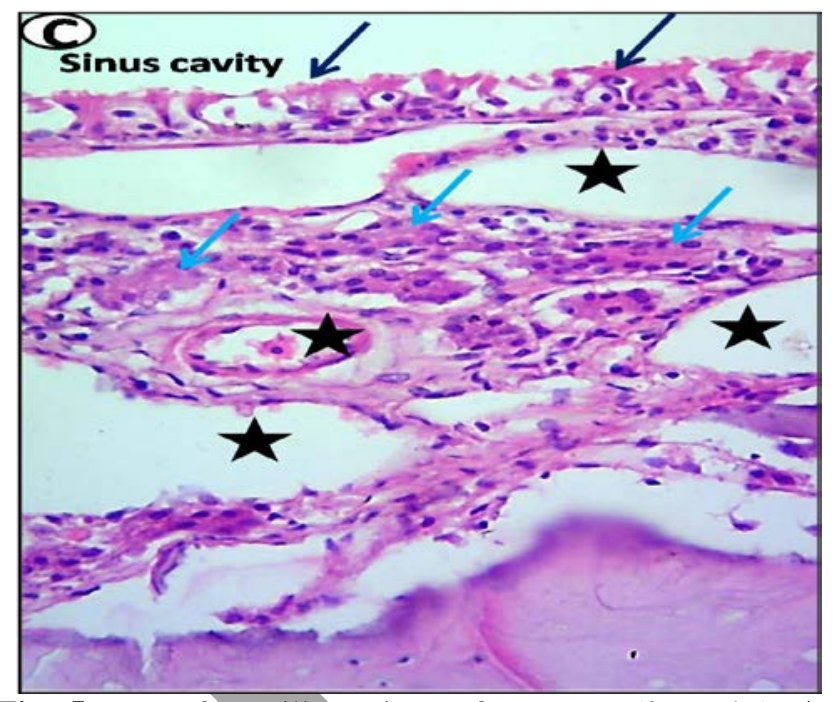

Fig. 5: LM of maxillary sinus of group II (8 weeks). A: showing the almost complete regeneration of mucous membrane lining the sinus cavity and the density of the underlying mature lamellar bone, B: showing the marked vascularity (arrows) of the lamina propria of the regenerated sinus mucosa, C:LM of higher magnification of the previous micrograph inset showing the pseudostratified ciliated columnar epithelium with many goblet cells (black arrows), serous acini (blue arrows) and numerous blood vessels (stars) in the underlying connective tissue.(H\&E, A, B: x100, C: x400).

\section{III- Histomorphometric analysis:}

The mean area percent of newly-formed bone in the two groups at 2 and 8 weeks intervals is summarized by mean and standard deviation in Table (1). At 2 weeks, signs of bone formation were noted in group II more than group I $(\mathrm{P}<0.001)$, where the mean area percent of new bone formation in group II was found to be $33.4 \% \pm 2.3$, while that of group I was $12.6 \% \pm 2.0$. At 8 weeks, the calculated mean area percent of the newly formed bone in group II was $53.3 \% \pm 2.2$, which was higher than that in group I which was $51.9 \% \pm 2.0$.

Table (1): Comparison between the different studied periods and groups according to percentage of bone surface area (\%)

\begin{tabular}{|l|l|l|l|l|}
\hline $\begin{array}{c}\text { Bone } \\
\text { Surface } \\
\text { area (\%) }\end{array}$ & \multicolumn{1}{|c|}{$\begin{array}{c}\text { Group I } \\
(\mathbf{n}=\mathbf{5})\end{array}$} & $\begin{array}{c}\text { Group II } \\
(\mathbf{n}=\mathbf{5})\end{array}$ & $\mathbf{t}$ & $\mathbf{p}$ \\
\hline 2 Weeks & & & & \\
\hline $\begin{array}{l}\text { Median } \\
\text { (Min.Max.) } \\
\text { Mean } \pm \text { SD. }\end{array}$ & $12.5(10.2-15.3)$ & $33.1(30.4-36.1)$ & $15.389^{*}$ & $<0.001^{*}$ \\
\hline 8 Weeks & $12.6 \pm 2.0$ & $33.4 \pm 2.3$ & & \\
\hline $\begin{array}{l}\text { Median } \\
\text { (Min.Max.) }\end{array}$ & $51.8(49.4-54.3)$ & $53.2(50.5-56.1)$ & 1.120 & 0.295 \\
Mean \pm SD. & $51.9^{\#} \pm 2.0$ & $53.3^{\#} \pm 2.2$ & & \\
\hline
\end{tabular}

T: Student t-test

$\mathrm{p}_{0}$ : $\mathrm{p}$ value for comparing between group I and group II

\#: Statistically significantfor comparing between 2 Weeks and 8

Weeks

*: Statistically significant at $\mathrm{p} \leq 0.05$ 


\section{DISCUSSION}

Sinus lifting procedures have become a prospective and effective treatment, performed when there is insufficient bone height for primary implant placement due to the maxillary alveolar ridge atrophy. If no troubles occurred during the postoperative course, the outcome is highly expected (4, 23, and 24). One of the most common complications is sinus membrane perforation during the treatment, which makes implant placement difficult (3).

In the present study, we used the amniotic membrane to evaluate its effect on healing of sinus defect in a rabbit model.

The New Zealand white rabbits were selected for our experimental study. Rabbits are considered to be an easily available type of animals which makes them a promising model for research purposes. They are commonly used for research activities including various branches of medical and dental sciences because these strains are less violent and healthier than other breeds (25).

Moreover, the selection of a healthy large animal, as rabbits, with an average weight of 2.5 to $3.0 \mathrm{~kg}$ makes them capable of withstanding surgical trauma, preventing most of the problems occurred postoperatively thus resulting in a better survival rate (25).

Simplifying this work highlighted two points, first; the histological and histomorphometric evaluation of the healing progress of maxillary sinus membrane perforation in rabbits after using the amniotic membrane. Second, compare the results with fibrin glue which was used as a control group.

In our procedure we used the same shape and size of trephine bur to do the standardized sinus windows thus, minimizing procedural errors and providing properly the same circumstances for comparison between group I and II in each rabbits introduced by Hyunmin et al (26) and Abdussamad et al (20).

The histological results at two weeks postoperative of group II (amniotic membrane group) revealed; the repair of sinus membrane by an almost continuous layer of pseudostratified ciliated columnar epithelium with many goblet cells, while in group I (fibrin glue group) the sinus membrane epithelium was immature and discontinuous.

This faster rate of reepithelialization of maxillary sinus membrane perforation seen in the amniotic membrane group was in agreement with both Kim et al (27)who showed increased epithelialization in alkali-burned corneal surface transplanted with amniotic membrane and Heiligenhaus et al (28) who showed the same results in experimental herpetic keratitis also using amniotic membrane transplantation.

This was also in agreement with Loeffelbein et al (29) who revealed that the basement membrane formation acceleration in wounds treated with AM that might be as a result of growth factors release.

Moreover, Azuara-Blanco et al (30) stated that the AM produced an appropriate substrate, such as laminins for rapid epithelial cells attachment and stimulate rapid proliferation of cells, differentiation, inhibition of inflammation, and fibrosis where the AM is a fibrous tissue proliferation barrier.
It has been demonstrated that the AM speed up the maturation of keratinocytes and epithelialization process. Besides acting as a scaffold for epithelial cell migration and support the basal epithelial cells, AM contains various growth factors that stimulate epithelialization, promote epithelial differentiation and prevent its apoptosis $(29,18)$.

The results of the present study revealed that the amount of bone formation is increased in group II than in group I at both $2 \& 8$ weeks. These results corporate with those of Samandari et al (31) who found significant increase in bone deposition in vestibuloplasty cases treated with human amniotic membrane which may be explained by In't Anker et al (32) who demonstrated the bipotential osteogenic and adipogenic differentiation of AM due to its high content of mesenchymal stem cells.

Amniotic membrane was found to be capable of rapid wound improvement and bone induction. That might be explained by its content of collagen, fibronectin and laminin, all of which provide a suitable substrate for bone induction. Also, this substrate helps in the induction of progenitor cells and/or stem cells in the surgical area into osteoblasts through its growth factor content, thus stimulating new bone formation (31).

Furthermore, a clinical trial made by Kumar et al (33) to evaluate amniotic membrane using with bone graft in treatment of interdental defects. There was an increase in the amount of bone fill and decrease in the inflammation indicated by decrease in the levels of interleukin $1 \beta$ in gingival crevice fluid.

In the present study, one of the most important findings was the obvious vascularity of the lamina propria of the sinus mucosa in group II at both 2 \&8 weeks which were in accordance with the work of Faulk et al (34) who demonstrated that the human amnion membrane transplantation could induce neovascularization in human leg ulcers.

Also, this relevant result was in agreement with Rinastiti et al (35) who declared that formation of granulation tissue in the gingival wound is rapidly stimulated by amniotic membrane by rapid induction of fibroblasts and vascularization.

This finding may be attributed to the fact that fibroblast growth and neovascularization in the gingival wound may be stimulated by the growth factors content of the amniotic membrane such as bFGF, TGF- $\beta$ and interleukin-1 (IL-1) $(36,37)$.

On the other hand, previous studies revealed that in vivo and in vitro transplantation of amniotic membrane on the cornea suppressed neovascularization $(38,39)$.

Rinastiti et al (35) assumed that following transplantation with human amniotic membrane, the wound healing neovascularization is depending on the anatomical site of the wound, being that suppression of neovascularization induced by amniotic membrane may just happen in the corneal wound.

In 2014, Niknejad and Yazdanpanah (40)demonstrated that vessel sprouting is inhibited by the epithelial side of the $\mathrm{AM}$ in addition to capillary numbers reduction; while angiogenesis is increased by the mesenchymal side of the 
AM thus they assumed that the antiangiogenic effect of AM was side dependent. So, advanced studies are recommended to define this argument.

The amniotic membrane in this study showed a great value in acceleration of the repair of perforated maxillary sinus membrane with good blood supply and shows better histological evidence of bone healing and formation.

\section{CONCLUSIONS}

According to the present study results, it was concluded that the amniotic membrane is effective in the repair of perforated sinus membrane with superior potentiality than fibrin glue especially in the early stage. In addition to its ability to induce new bone formation with almost complete filling of the defects. Furthermore, the remarkable finding regarding its angiogenic capability which was not observed in the fibrin glue group.

\section{CONFLICT OF INTEREST}

The authors declare that they have no conflicts of interest.

\section{REFERENCES}

1. Hernndez-Alfaro F, Torradeflot MM, Marti C. Prevalence and management of Schneidarian membrane perforations during sinus-lift procedures. Clin Oral Implants Res 2008; 19: 91-8.

2. Konter U, Pape HD. Oroantral fistula and maxillary sinusitis after the sinus lift. Dtsch Z Mund Kiefer GesichtsChir 1995; 19: 32-4.

3. Aimetti M, Romagnoli R, Ricci G, Massei G. Maxillary sinus elevation: the effect of macrolacerations and microlacerations of the sinus membrane as determined by endoscopy. Int J Periodontics Restorative Dent 2001; 21: 581-9.

4. Pikos MA. Maxillary sinus membrane repair: update on technique for large and complete perforations. Implant Dent 2008; 17: 24-31.

5. Pikos MA. Maxillary sinus membrane repair: report of a technique for large perforations. Implant Dent 1999; 8: 29-34.

6. Proussaefs P, Lozada J, Kim J. Effects of sealing the perforated sinus membrane with a resorbable collagen membrane: a pilot study in humans. J Oral Implantol 2003; 29: 235-41.

7. Choi BH, Zhu SJ, Jung JH. Cyanoacrylate adhesive for closing sinus membrane perforations during sinus lifts. J Craniomaxillofac Surg 2006; 34: 505-9.

8. Choi BH, Zhu SJ, Jung JH,Lee S,Huh J. The use of autologous fibrin glue for closing sinus membrane perforations during sinus lifts. Oral Surg Oral Med Oral Pathol Oral Radiol Endod 2006; 101: 150-4.

9. Davis B, Sandor GKB. Use of fibrin glue in maxillofacial surgery. J Otolaryngol 1998; 27: 107-12.

10. Danforth DN, Hull RW. The microscopic anatomy of the fetal membranes with particular reference to the detailed structure of the amnion. Am J Obstet Gynecol. 1958; 75:536-47.

11. Bourne GL. The microscopic anatomy of the human amnion and chorion. Am J Obstet Gynecol. 1960; 79:1070-10.
12. Díaz-Prado S, Rendal-Vázquez ME, Muiños-López E, Hermida-Gómez T, Rodríguez-Cabarcos M, FuentesBoquete I, de Toro FJ, Blanco FJ. Potential use of the human amniotic membrane as a scaffold in human articular cartilage repair. Cell Tissue Bank. 2010; 11:183-95.

13. Hennerbichler S, Reichl B, Pleiner D, Gabriel C, Eibl J, Redl $\mathrm{H}$. The influence of various storage conditions on cell viability in amniotic membrane. Cell Tissue Bank. 2007; 8:1-8.

14. Shortt AJ, Secker GA, Lomas RJ, Wilshaw SP, Kearney JN, Tuft SJ, Daniels JT. The effect of amniotic membrane preparation method on its ability to serve as a substrate for the ex-vivo expansion of limbal epithelial cells. Biomaterials. 2009; 30:1056-65.

15. TsengSCG, PrabhasawatP, LeeSH. Amniotic membrane transplantation for conjunctival surface reconstruction. Am J Ophthalmol1997; 124:765-774.

16. Samandari MH, Yaghmaei M, Ejlali M, Moshref M, Saffar AS. Use of amnion as a graft material in vestibuloplasty: a preliminary report. Oral Surg Oral Med Oral Pathol Oral Radiol Endod. 2004; 97:574-8.

17. Toda A, Okabe M, Yoshida T, Nikaido T. The potential of amniotic membrane/amnion-derived cells for regeneration of various tissues. J Pharmacol Sci 2007; 105: 215-28.

18. Mamede AC, Carvalho MJ, Abrantes AM, Laranjo M, Maia CJ, Botelho MF. Amniotic membrane: from structure and functions to clinical applications. Cell Tissue Res 2012; 349: 447- 58.

19. Kesting MR, Loeffelbein DJ, Classen M, SlottaHuspenina J, Hasler RJ, Jacobsen F, Kreutzer K, AlBenna S, Wolff K, Steinstraesser L. Repair of oronasal fistulas with human amniotic membrane in minipigs. $\mathrm{Br}$ J Oral Maxillofac Surg. 2010; 48:131-135.

20. Abdussamad RAE, Sadakah AA, Gab Allah OM, Nowair IM. Evaluation of maxillary sinus membrane repair using two different sutureless techniques. Tanta Dent J. 2015; 12:225-34.

21. Priemel M, von Domarus C, Klatte TO, Kessler S, Schlie J, Meier S, Proksch N, Pastor F, Netter C, Streichert $\mathrm{T}$, Püschel $\mathrm{K}$, Amling $\mathrm{M}$. Bone mineralization defects and vitamin $\mathrm{D}$ deficiency: histomorphometric analysis of iliac crest bone biopsies and circulating 25-hydroxyvitamin D in 675 patients. J. of Bone and Miner Res. 2010;25:305-12.

22. Parfitt AM, Drezner MK, Glorieux FH, Kanis aja, Malluche H, Meunier PJ, Ott SM, Recker RR. Bone histomorphometry: standardization of nomenclature, symbols, and units: report of the ASBMR Histomorphometry Nomenclature Committee. J Bone Miner Res 1987; 2:595-610.

23. Wiltfang J, Schultze-Mosgau S, Nkenke E, Thorwarth M, Neukam FW, Schlegel KA. Onlay augmentation versus sinuslift procedure in the treatment of the severely resorbed maxilla: a 5-year comparative longitudinal study. Int J Oral Maxillofac Surg. 2005; 34:885-9.

24. Cha HS, Kim A, Nowzari H, Chang HS, Ahn KM. Simultaneous sinus lift and implant installation: prospective study of consecutive two hundred seventeen 
sinus lift and four hundred sixty-two implants. Clin Implant Dent Relat Res. 2014; 16:337-47.

25. Baumans V. Environmental enrichment for laboratory rodents and rabbits: requirements of rodents, rabbits, and research. ILAR J. 2005; 46:162-70.

26. Choi H, Park NJ, Jamiyandorj O, Choi KH, Hong MH, $\mathrm{Oh} \mathrm{S}$ et al. Improvement of osteogenic potential of biphasic calcium phosphate bone substitute coated with two concentrations of expressed recombinant human bone morphogenetic protein. J Periodontal Implant Sci 2012; 42:119-26.

27. Kim JS, Kim JC, Na BK, Jeong JM, Song CY. Amniotic membrane patching promotes healing and inhibits proteinase activity on wound healing following acute corneal alkali burn. Exp Eye Res. 2000; 70:32937.

28. Heiligenhaus A, Bauer D, Meller D, Steubl KP, Tseng SCG. Improvement of HSV-1 necrotizing keratitis with amniotic membrane transplantation. Invest Ophthalmol Vis Sci. 2001; 42:1969-74.

29. Loeffelbein DJ, Rohleder NH, Eddicks M, Baumann CM, Stoeckelhuber M, Wolff K, Drecoll E, Steinstraesser L, Hennerbichler S, Kesting MR. Evaluation of human amniotic membrane as a wound dressing for split-thickness skin-graft donor sites. BioMed Res Int. 2014; 2014:572-183.

30. Azuara-Blanco A, Pillai CT, Dua HS. Amniotic membrane transplantation for ocular surface reconstruction. Br J Opthalmol. 1999; 83:399-402.

31. Samandari M, Adibi S, Khoshzaban A, Aghazadeh S, Dihimi P, Torbaghan SS, Keshel SH, Shahabi Z. Human amniotic membrane, best healing accelerator, and the choice of bone induction for vestibuloplasty technique (an animal study). Transpalnt Res Risk Manage. 2011;3:1-8.
32. In't Anker PS, Scherjon SA, Kleijburg-van der Keur C, de Groot-Swings GMJS, Claas FHJ, Fibbe WE, Kanhai HHH. Isolation of mesenchymal stem cells of fetal or maternal origin from human placenta. Stem Cells. 2004; 22:1338-45.

33. Kumar A, Chandra RV, Reddy AA, Reddy BH, Reddy C, Naveen A. Evaluation of clinical, antiinflammatory and antiinfective properties of amniotic membrane used for guided tissue regeneration: a randomized controlled trial. Dent Res J. 2015; 12:127.

34. Faulk WP, Matthews R, Stevens PJ, Bennett JP, Burgos $\mathrm{H}$, His BL. Human amnion as an adjunct in wound healing. Lancet. 1980; 1:1156-58.

35. Rinastiti M, Harijadi AL, Santoso ALS, Sosroseno W. Histological evaluation of rabbit gingival wound healing transplanted with human amniotic membrane. Int J Oral Maxillofac Surg. March 1, 2006; 35:247-51.

36. Koizumi $\mathrm{N}$, Inamoto $\mathrm{T}$, Sotozono $\mathrm{T}$, Fullwood $\mathrm{NJ}$, Quantock AJ, Kinosita S. Growth factors mRNA and proteins in preserved human amniotic membrane. Curr Eye Res. 1997; 20:173-7.

37. Rote NS, Menon R, Swan KF, Lyden TW, Fortunato SJ. Expression of IL-1 and IL-6 protein and mRNA in amniochorionic membrane. Placenta. 1993; 14:A63.

38. Kobayashi N, Kabuyama Y, Sasaki S, Kato K, Homma Y. Suppression of corneal neovascularization by culture supernatantof human amniotic cells. Cornea. 2002; 21:62-7.

39. Shao C, Sima J, Zhang SX, Jin J, Reinach P, Wang Z, Ma JX. Suppression of corneal neovascularization by PEDF release from human amniotic membranes. Invest Ophthalmol Vis Sci. 2004; 45:1758-62.

40. Niknejad H, Yazdanpanah G. Opposing effect of amniotic membrane on angiogenesis originating from amniotic epithelial cells. J Med Hypo Ideas. 2014; 8:39-

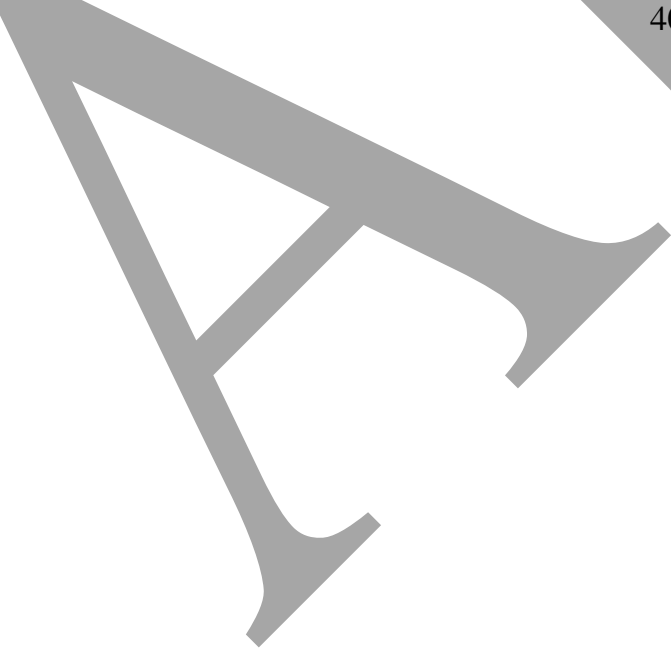

